\title{
Experimental investigation on condensation of vapor in the presence of non-condensable gas on a vertical tube
}

\author{
Shengjun Zhang ${ }^{1,}$, Feng Shen ${ }^{1}, \mathrm{Xu}$ Cheng ${ }^{2}$, Xianke Meng1 ${ }^{1}$, Dandan $\mathrm{He}^{1}$ \\ ${ }_{1}^{1}$ State Power Investment Central Research Institute, Beijing Future Sincere Park, Changping District, Beijing, P.R. China, \\ 2 Shanghai Jiao Tong University, School of Nuclear Science and Engineering, Shanghai, , P.R. China \\ *Correspondence: e-mail zhang_rn@163.com; Tel:+86-010-56681652
}

\begin{abstract}
According to the operation conditions of time unlimited passive containment heat removal system(TUPAC), a separate effect experiment facility was established to investigate the heat transfer performance of steam condensation in presence of non-condensable gas. The effect of wall subcooling temperature, total pressure and mass fraction of the air on heat transfer process was analyzed. The heat transfer model was also developed. The results showed that the heat transfer coefficient decreased with the rising of subcooling temperature, the decreasing of the total pressure and air mass fraction. It was revealed that Dehbi's correlation predicted the heat transfer coefficient conservatively, especially in the low pressure and low temperature region. The novel correlation was fitted by the data obtained in the following range: $0.20 \sim 0.45 \mathrm{MPa}$ in pressure, $20 \% \sim$ $80 \%$ in mass fraction, $15^{\circ} \mathrm{C} \sim 45^{\circ} \mathrm{C}$ in temperature. The discrepancy of the correlation and experiment data was with $\pm 20 \%$.
\end{abstract}

Keywords: Condensation; Non-condensable gas; Experimental Study; Containment cooling

\section{Introduction}

Containment is the last safety barrier for nuclear power plants to prevent the release of radioactive fission products. The third generation of nuclear power technology has set up a proprietary passive safety system to ensure the integrity of nuclear power plants $72 \mathrm{hr}$ after the accident. After the Fukushima nuclear accident, how to further improve the passive heat removal capacity of containment cooling system is a completely new challenge for existing nuclear power plants. Then, a novel passive containment cooling system (PCCS) is proposed and investigated to extend the passive cooling capacity of containment of AP1000 after 72hr named as TimeUnlimited passive containment cooling system(TUPAC). As is shown in Figure.1, it is consisted of the internal heat exchanger, air cooler, riser and downcomer. During a LOCA or a MSLB accident, non-condensable gases (hydrogen, air, etc.) mixed with the steam will be injected into the containment. The fluid in the internal heat exchanger will be heated by the condensation of steam mixed with non-condensable gases (hydrogen, air, etc.) outside the tube bundles. Driven by the height and density difference of internal heat exchanger and air cooler, the residual heat is transferred to the air cooler outside of containment passively. The fluid in air cooler is then cooled in the chimney. In the above process, the condensation heat transfer of steam in presence of the noncondensable outside the tube of internal heat exchanger is an important factor affecting the heat removal capacity of the TUPAC system. 


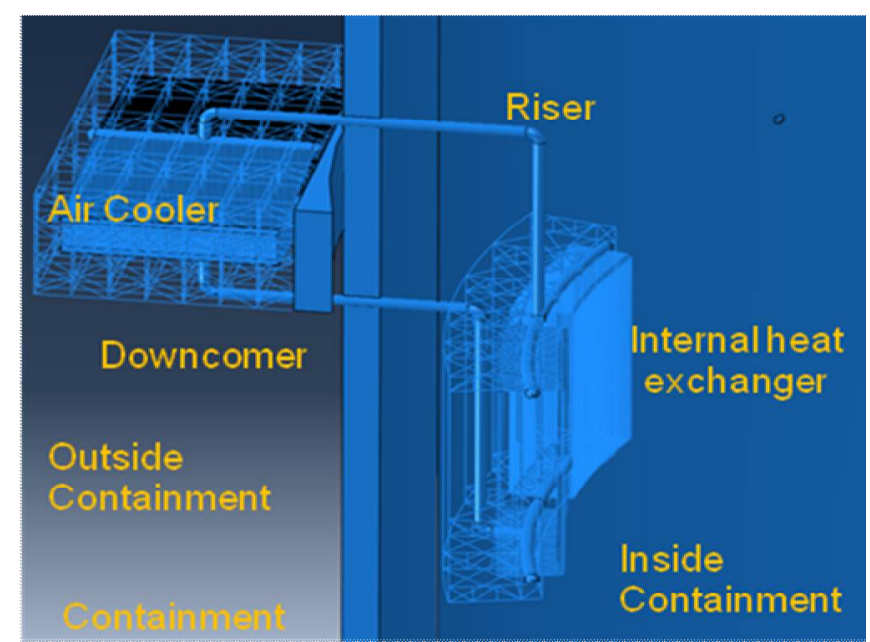

Figure 1. The scheme of time unlimited passive containment heat removal system

Since the presence of non-condensable gas hinders the heat transfer process of steam condensing, the heat and mass transfer process are very different from the pure steam condensing. At present, many scholars have carried out relevant experimental studies. Uchida [2] and Tagami [3] have obtained the correlations that were widely used under atmospheric conditions, but only considered the influence of the single parameter of air mass fraction on the heat transfer coefficient and cannot reflect other factors in the heat transfer process. Dehbi [4] considered the factors such as pressure, non-condensable gas content and wall subcooling temperature, and obtained a wide range of empirical correlations. However, due to limitations of the test facility function and measurement scheme, the experimental results of the heat transfer were relatively conservative. The thermocouple wire was pressed under the copper on the outer surface of test section to measure the wall temperature, which introduced an additional thermal resistance and result in low measurement of wall temperature. Then, the experiment heat transfer coefficient was under-estimated. At the same time, due to the limited flow condition of the pump, the temperature difference between the inlet and outlet of the test section under the condition of low air mass fraction or large wall subcooling temperature was large (part of the working temperature difference is more than $10^{\circ} \mathrm{C}$ ), which also affected the measurement of the average heat transfer temperature difference. Liu [5] tested under the condition that the cooling water temperature was close to $100{ }^{\circ} \mathrm{C}$ and the wall sub-cooling was low. The empirical formula was obtained by multiple linear regression, but the trend of effect of wall subcooling temperature on the condensation heat transfer coefficient was opposite to that of Dehbi. Su [6, 7] studied the influence of various parameters on condensation heat transfer under high pressure and large wall subcooling temperature conditions. The results correlated by an empirical formulation, which the influence of various parameters on the condensation heat transfer could be well reflected. However, the data in low pressure and low subcooling temperature were not obtained, which was very important for TUPAC. Lee [8] provided an empirical correlation with $\mathrm{Nu}, \mathrm{Gr}$ and Ja number. But the length of test section is only $1 \mathrm{~m}$. The previous analysis and experimental results [4] showed that the liquid film outside the test section would not be fully developed and non-condensable gas concentration was uneven distributed, which could result in a higher heat transfer coefficient. In addition, deviations also existed in the same experimental conditions for different correlations. Figure 2 shows the deviation of the heat transfer coefficient calculated by Su's [7] and Dehbi's [4] correlation. The results showed that the difference of the two correlations reached $25 \%-40 \%$ under the condition of $30{ }^{\circ} \mathrm{C}$ of the wall subcooling temperature with different air mass fraction. And $\mathrm{Su}$ [9] also pointed out in the literature that Dehbi's prediction was obviously smaller. 


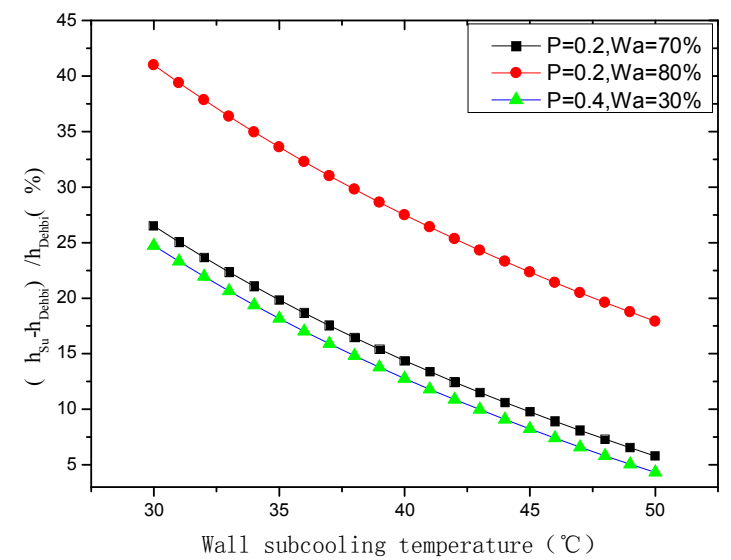

Figure 2. Comparison of Dehbi and Su's Correlation results

As the TUPAC system operates after the $72 \mathrm{hr}$ of accident, the pressure and temperature are relatively low. And some heat transfer data needs to be further verified and supplemented. Therefore, the test parameter are set as below: pressure range of containment is $0.20 \sim 0.4 \mathrm{MPa}$, non-condensable gas mass fraction is $35 \% \sim 80 \%$ and the subcooling temperature of the wall is $15 \sim 50{ }^{\circ} \mathrm{C}$. The condensation heat transfer experiment outside the tube is carried out.

\section{Experimental System and Method Analysis}

\subsection{Experimental system}

Figure 3 is a schematic diagram of the test facility. The facility consists of a containment simulator, internal heat exchanger test section, air supply system, cooling water circulation system and measurement control system. As shown in Figure 3, the containment simulator is a carbon steel cylindrical tank with an outer diameter of $1.5 \mathrm{~m}$ and a total height of $4 \mathrm{~m}$. Four heating rods with a heating power of $15 \mathrm{~kW}$ are installed at the bottom to provide steam to the test system. The internal heat exchanger test section is located in the containment center, with $2.0 \mathrm{~m}$ in length, $38 \mathrm{~mm}$ in diameter, $1 \mathrm{~mm}$ in thickness. The mass fraction of the helium and air in the containment can be adjusted by the inlet and exhaust valves located at the bottom and top of the tank. Non-condensable gas and steam mixed in the containment and condensed on the test section. Figure 4 shows the overview of the test facility.

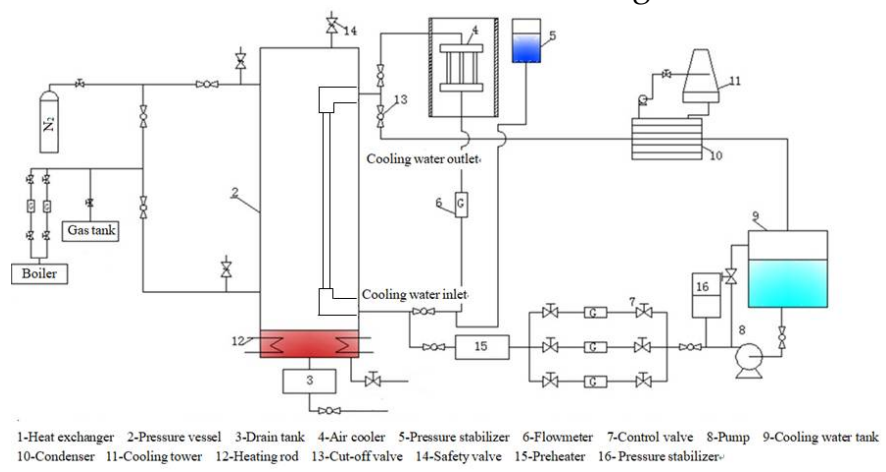

Figure 3. Flowchart of TUPAC-SPTF 


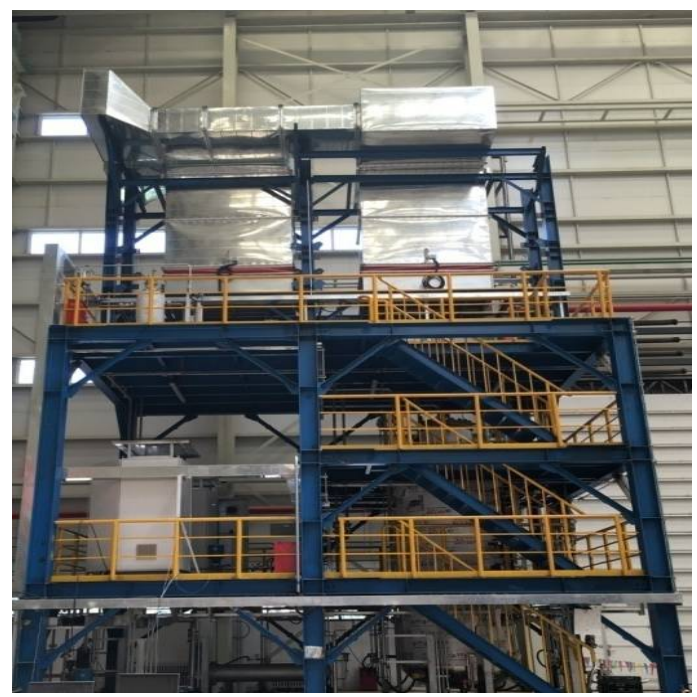

Figure 4. Overall view of experiment facility

The test facility fully draws on the experience of Dehbi's facility. The following improvements were made in measurement and control methods:

1. In the test section, thermocouples are arranged on both sides of 9 different heights in the axial direction. In order to obtain a stable wall temperature of the test section, a groove is formed on the outer wall of the circular pipe and the depth of the groove is measured. A T-type thermocouple wire is welded in the outer wall of the slot to measure the wall temperature; in the same cross-section height, $80 \mathrm{~mm}$ from the outer wall of the test section, thermocouples are placed to measure the ambient temperature of the containment;

2. Considering the influence of temperature rise of cooling water inlet and outlet on the distribution of wall subcooling temperature, the temperature difference between inlet and outlet of cooling water is always controlled between $4{ }^{\circ} \mathrm{C}$ and $5{ }^{\circ} \mathrm{C}$ throughout the test;

3. Error analysis results shows that the accuracy of inlet and outlet temperature of test section and cooling flow measurement has a greater impact on the uncertainty of results. So, mass flowmeters with accuracy of $0.15 \%$ are installed and thermal resistances with the accuracy of $\pm 0.2{ }^{\circ} \mathrm{C}$ are implemented on the inlet and outlet of test section.

4. Cooling water loop water tank can be pressurized to achieve a test condition of small wall subcooling temperature at low air mass fraction or high containment pressure conditions.

In order to reduce the effect of the entrance effect, the horizontal section and the small part of the vertical section at both ends of the test section are wrapped in the thermal insulation layer.

2.2. Experimental data treatment

By analyzing the experimental data of condensation heat transfer outside the vertical tube, the factors affecting the heat transfer are obtained. The experimental data are fitted and the empirical correlation is given. Experimental data processing mainly consists of two parts: one is to determine the composition of mixed gases, the other part is to determine the heat transfer tube condensation heat transfer coefficient. The test has measured the total pressure of mixed gas $\mathrm{P}$, mixture average temperature $\overline{T_{b}}$ and wall temperature average $\overline{T_{w}}$.

Under steady-state conditions, the partial pressure of air is obtained by subtracting the partial pressure of steam from the total pressure in the condensing tank. The steam is assumed to be saturated and both air and steam are considered as ideal gases. According to Dalton partial pressure law:

$$
\frac{m_{a}}{m_{v}}=\frac{P_{a}}{P_{v}\left(\overline{T_{b}}\right)} \cdot \frac{M_{a}}{M_{v}}
$$

In the formula, $m$-mass, $\mathrm{kg}$; $M$-molecular weight, $\mathrm{kg} / \mathrm{mol}$; a-air; v-steam. 
Therefore, the ratio of air mass to steam mass is:

The mass fraction of air $W_{a}$ is:

$$
\frac{m_{a}}{m_{v}}=\frac{29\left(P-P_{v}\left(\overline{T_{b}}\right)\right)}{18 P_{v}\left(\overline{T_{b}}\right)}
$$

$$
W_{a}=\frac{m_{a}}{m_{a}+m_{v}}=\frac{29 P-29 P_{v}\left(\overline{T_{b}}\right)}{29 P-11 P_{v}\left(\overline{T_{b}}\right)}
$$

In the same way, the volume fraction of the air and steam in the mixture can be determined according to the measured total pressure and the vapor pressure, which is determined by the main stream temperature.

The condensation heat transfer capacity tube is calculated by the water side.

$$
Q=m_{r} c_{p}\left(t_{2}-t_{1}\right)
$$

In the formula, $Q$ - condensate heat transfer, $\mathrm{kW} ; m_{r}$ - mass flow of cooling water, $\mathrm{kg} / \mathrm{s} ; \mathrm{t}_{2}$ - cooling water outlet temperature, ${ }^{\circ} \mathrm{C} ; t_{1}$ - cooling water outlet temperature, ${ }^{\circ} \mathrm{C}$.

Ignoring the loss of heat generated by the axial heat conduction in the test section, the heat released by the steam is equal to the heat absorbed by the cooling water from the conservation of energy, and the average condensation heat transfer coefficient of the test section is obtained:

$$
\overline{h_{0}}=\frac{m_{r} c_{p}\left(t_{2}-t_{1}\right)}{A\left(\overline{T_{b}}-\overline{T_{w}}\right)}
$$

According to the accuracy of each measuring instrument and test range, the minimum temperature difference of cooling water in this experiment is $4^{\circ} \mathrm{C}$, the minimum temperature difference of wall subcooling temperature is $15{ }^{\circ} \mathrm{C}$, and the maximum relative uncertainty of condensation heat transfer coefficient is $15.75 \%$.

\section{Analysis of experimental results}

In this paper, the condensation heat transfer process is mainly affected by the wall subcooling temperature, pressure and air mass fraction, in order to accurately study the relationship between each parameter and the condensation heat transfer coefficient, the experiment will examine each effect of these factors on the condensation heat transfer coefficient. In order to verify the accuracy of the test results, the experiments were carried out within the scope of the previous empirical correlations, and the results show that the experimental results are in good agreement with the Su's correlation formula. Then the test of low pressure and low subcooling condition is carried out, and the effect of subcooling temperature, total pressure and air mass fraction on the heat transfer coefficient respectively is obtained. Finally, the empirical correlation is fitted.

\subsection{Comparative analysis and evaluation}

The comparison between experimental results and $\mathrm{Su}$ empirical correlations under different parameters is shown in Figure.5 and Figure. 6. The results show that the experimental data can be well fitted with the correlation of Su. Within the applicable range of Su (2013) [9], the deviation from calculation and test results is less than $15 \%$, and the deviation from the test result is less than $10 \%$ within the applicable range of Su (2014) [10] 


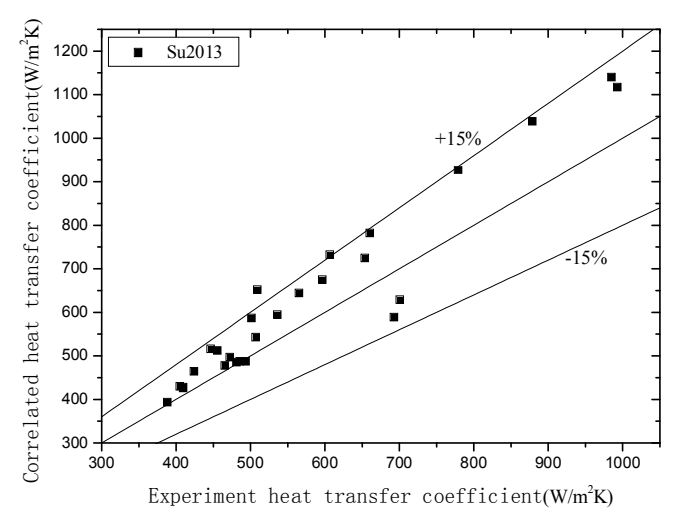

Figure 5. Comparison of data with $\mathrm{Su}(2013)$ 's results

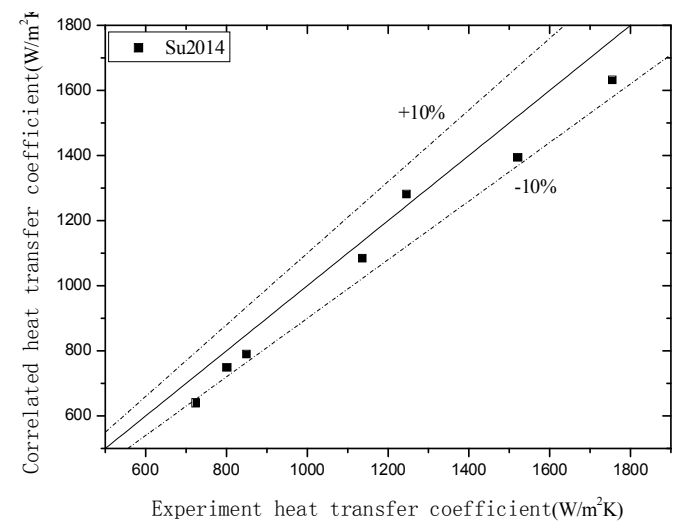

Figure 6. Comparison of data with $\mathrm{Su}(2014)$ 's results

\subsection{Effect of wall subcooling temperature}

Wall subcooling temperature is an important factor that affects the condensation heat transfer. During the test, the inlet temperature and circulating water flow of the cooling water are adjusted to adjust the wall temperature of the test section. By adjusting the simulation body of the containment heating power, adjust the ambient temperature inside the containment, so as to realize the accurate control of subcooling temperature on the wall. As shown in Figure. 7, when the total pressure and the mass fraction of air are constant, the curve of the condensation heat transfer coefficient changes with the subcooling temperature of the wall. When the subcooling temperature of the wall increases, the condensation heat transfer coefficient shows a downward trend, which is consistent with the trend of $\mathrm{Su}$, Dehbi and other models. Under the condition of total pressure $0.4 \mathrm{MPa}$ and air mass fraction $60 \%$, the heat transfer coefficient increased $35.6 \%$ when the wall temperature decreased from $50^{\circ} \mathrm{C}$ to $16^{\circ} \mathrm{C}$. Under the condition of large wall subcooling temperature, more steam will transfer energy to the wall, and the condensation heat transfer will increase. However, the increase of heat transfer will also cause thickening of the liquid film and increase of thermal resistance, which leads to a negative relationship between the condensation heat transfer coefficient and the wall subcooling temperature. 


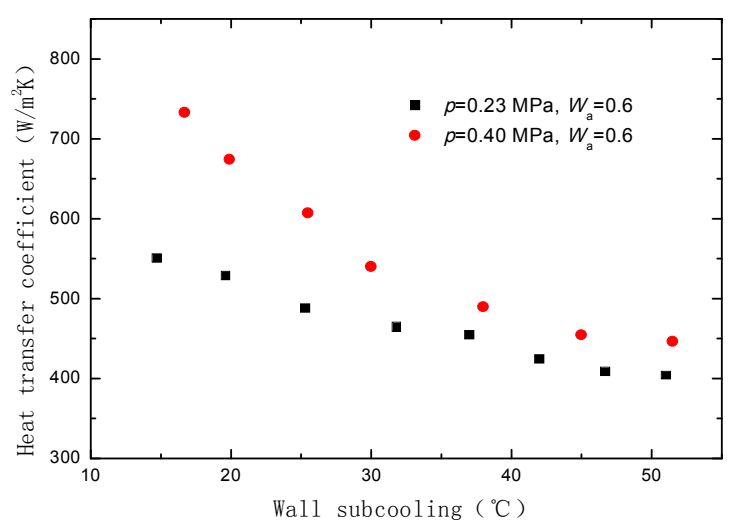

Figure 7. The effect of wall subcooling on condensation

\subsection{Effect of air mass fraction}

Figure 8 shows the change of condensation heat transfer coefficient with the air mass fraction under the same pressure condition. The results show that as the mass fraction decreases, the condensation heat transfer coefficient increases. Under the conditions of a total pressure of $0.23 \mathrm{MPa}$ and a wall subcooling temperature of $22.5^{\circ} \mathrm{C}$, the heat transfer coefficient increased by $36.9 \%$ when the mass fraction decreased from $50 \%$ to $40 \%$.This is due to the accumulation of non-condensable gases at the interface, so that the partial pressure of the non-condensable gases in the gas boundary layer is higher than the partial pressure of the mainstream non-condensable gases, resulting in a driving force to reversely diffuse non-condensable gases from the boundary layer interface. The partial pressure of steam in the mainstream gas is higher than that at the gas liquid interface. It provides driving force for the diffusion of steam to the interface. The diffusion of steam molecules to the condensing surface and the diffusion of non-condensable gas molecules to the mainstream direction maintain a dynamic equilibrium process of total pressure. The vapor molecules must pass through the non-condensable gas layer to reach the condensation wall surface. With the increase of the mass fraction of the non-condensable gas, the resistance of the mass transfer diffusion process increases, which further hinders the heat transfer rate and leads to the decrease of the heat transfer coefficient.

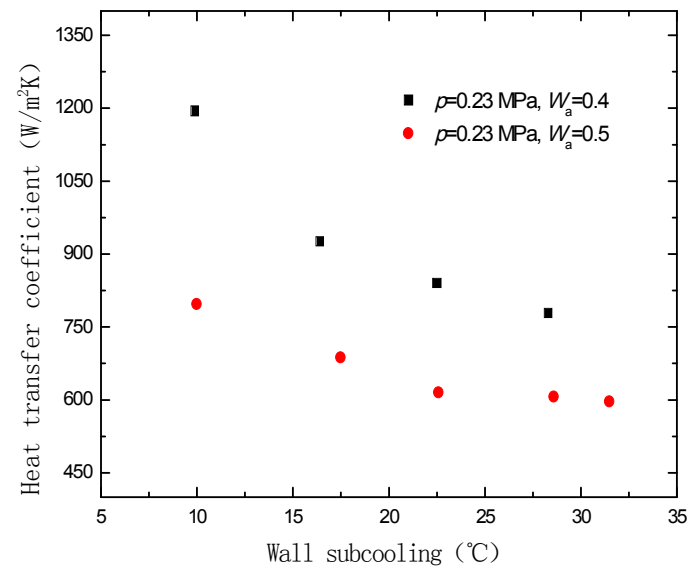

Figure 8. The effect of air mass fraction on condensation

\subsection{Effect of pressure}


Figure 9 shows the change of condensation heat transfer coefficient with pressure under $40 \%$ air mass fraction. The results show that as the pressure increases, the condensation heat transfer coefficient increases. The heat transfer coefficient increased by $26 \%$ when the pressure was increased from $0.3 \mathrm{MPa}$ to $0.4 \mathrm{MPa}$ at the subcooling temperature of $19{ }^{\circ} \mathrm{C}$. From the perspective of heat and mass transfer, the microscopic particles moves strenuously with the pressure and temperature increases, which accelerates heat and mass transfer process. In addition, the saturation temperature of the steam increases as the steam pressure increases, and the temperature difference between the mixed gas and the cooling water increases, thereby promoting heat transfer.

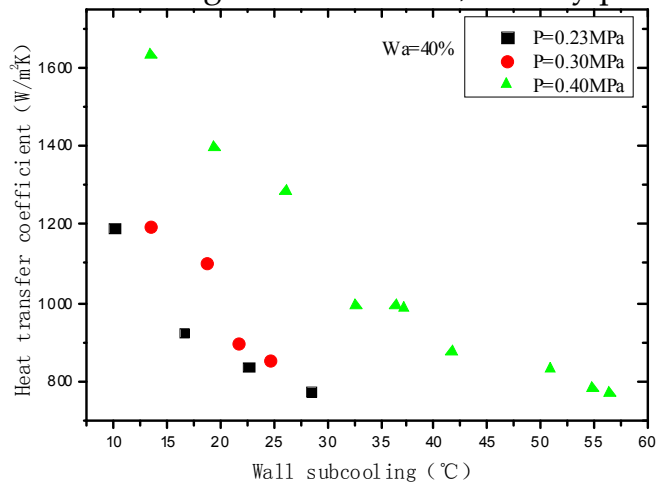

Figure 9. The effect of total pressure on condensation

\subsection{Fitting correlation}

In reference to $[7,9,10]$, it is assumed that the relationship between the wall subcooling temperature and the condensation heat transfer coefficient is exponential, and the effect of pressure and air mass fraction is considered , which have

$$
h_{0}=\left(T_{b}-T_{w}\right)^{\alpha} F\left(W_{a}, P\right)
$$

In the formula, $h_{0}$ is the condensation heat transfer coefficient, the $\alpha$ is the index term of the subcooling temperature, and the $F\left(W_{a}, P\right)$ is the function of the air mass fraction $W_{a}$ and the gas pressure $P$.

The value of $\alpha$ is -0.30 by linear regression of the index of subcooling temperature, and then the value of $F\left(W_{\mathrm{a}}, P\right)$ is calculated from the experimental parameters. As shown in Figure 10, the error between the experimental data and the fitted values for different wall subcooling temperature is within $\pm 4 \%$.

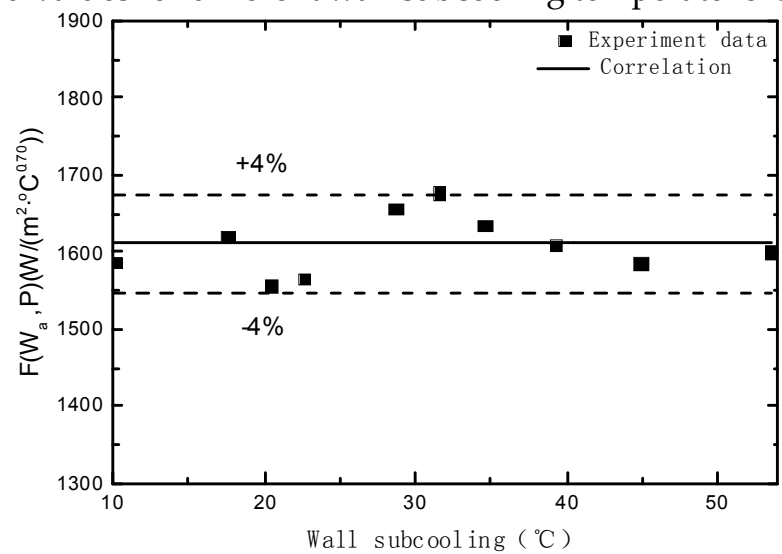

Figure 10. The $\mathrm{F}(\mathrm{Wa}, \mathrm{P})$ value after the wall subcooling effect rectified 
Finally, combined with the influence of wall subcooling temperature, we can get the experimental correlation of condensation heat transfer coefficient $h_{0}$ with the change of wall subcooling temperature, pressure and air mass fraction.

$$
h=\left(T_{\mathrm{b}}-T_{\mathrm{w}}\right)^{-0.30}\left[-3338.03 P+1014.31+(-121.18-19754.61 P) \log 10\left(W_{\mathrm{a}}\right)\right]
$$

Range of application: $0.35 \leq W_{\mathrm{a}} \leq 0.80 ; 0.20 \leq P \leq 0.40 \mathrm{MPa} ; 15 \leq T_{\mathrm{b}}-T_{\mathrm{cw}} \leq 50^{\circ} \mathrm{C}$.

Figure 11 shows the comparison between the experimental data and the correlation. The results show that the error between the correlation and the experimental result is within $\pm 20 \%$.

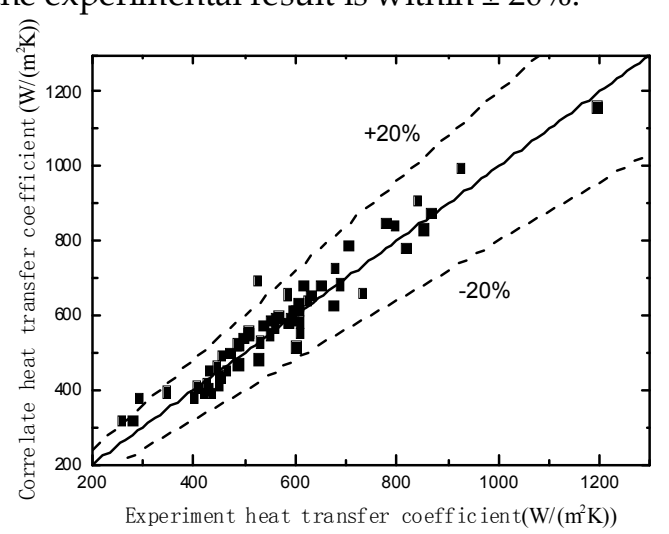

Figure 11. The discrepancy between the correlation and experiment data

\section{Conclusions}

The experimental study on the condensation heat transfer outside the tubes with non-condensable gas was carried out. In view of the operation environment of the TUPAC system, the existing heat transfer test data are supplemented and expanded under the condition of small wall subcooling and low pressure, and the following conclusions are drawn:

(1) In the application scope of Su's correlation, the calculated results can be fitted well with the experimental data.

(2) The influence of different factors on the condensation heat transfer is analyzed. The wall subcooling imposes an important effect on the condensation heat transfer coefficient. When the wall subcooling temperature increases, the condensation heat transfer coefficient decreased. And the condensation heat transfer coefficient increases with the decrease of air mass fraction and the increase of pressure.

(3) The experimental condensation heat transfer correlation related with the wall subcooling, pressure and air mass fraction is fitted. The deviation between the correlation and experimental data is less than $20 \%$.

Acknowledgments:National Science and Technology Major Project of the Ministry of Science and Technology o f China (No. 2015ZX06004004)

\section{References}

1. Shen, F, Zhang, S.J. Theoretical analysis of time-unlimited passive containment cooling system[C]. Topical Meeting on Nuclear Reactor Thermal Hydraulics, 2015, Beijing

2. Uchida, H, Oyama, A, Togo,Y. Evaluation of post-incident cooling systems of light-water power reactors. Proceedings of International Conference on Peaceful Uses of Atomic Energy[C]. Tokyo, 1965: 93-102.

3.Tagami,T. Interim report on safety assessments and facilities establishment project //Japanese Atomic Energy Research Agency [C].1965.

4.Dehbi, A.A. Analytical and experimental investigation of the effects of non-condensable gases on steam condensation under turbulent natural convection conditions[D]. US: M I T, 1990. 
5.Liu, H, Todreas, N.E, Driscoll, M.E. An experimental investigation of a passive cooling unit for nuclear plant containment [J]. Nuclear Engineering and Design, 2000, 199: 243-255.

6.Su J.Q, Sun, Z, Fan, G, et al. Experimental study of the effect of non-condensable gases on steam condensation over a vertical tube external surface[J]. Nuclear Engineering and Design, 2013, 262: 201-208.

7.Su J.Q, Sun, Z, Ding, M, et al. Analysis of experiments for the effect of noncondensable gases on steam condensation over a vertical tube external surface under low wall subcooling[J]. Nuclear Engineering and Design, 2014, 278: 644-650.

8.Lee, Y.G, Jang, Y,J, Choi, D.J. An experimental study of air-steam condensation on the exterior surface of a vertical tube under natural convection conditions. International Journal of Heat and Mass Transfer, 2017,104: 1034-1047.

9.Su, J.Q, Sun, Z, Gao, L. Analysis of experiments for steam condensation in presence of non-condensable gases with moderate wall subcooling [J]. Journal of Chemical Industry and Engineering, 2014, 65 (10): :3884-3890. 